\title{
Li Ziqi: Internet Idol or Cross-Cultural Communication Icon?
}

\author{
Devin Grace O'sullivan, GAO Yufang, GUO Zhengrong \\ College of Foreign Languages, Taiyuan University of Technology, China
}

Received: September 27, $2021 \quad$ Accepted: October 27, $2021 \quad$ Published: November 30, 2021

To cite this article: Devin Grace O'sullivan, GAO Yufang \& GUO Zhengrong. (2021). Li Ziqi: Internet Idol or Cross-Cultural Communication Icon?. Asia-Pacific Journal of Humanities and Social Sciences, 01: 3, 040-047, DOI: 10.53789/j.1653-0465. 2021.0103 .004

To link to this article: https: //doi.org/10.53789/ j.1653-0465.2021.0103.004

\begin{abstract}
Li Ziqi is extremely popular in China for her videos and has a moderate number of international fans. Cross -cultural communication is how people from different cultures can communicate, and there are many ways to analyze if an example of cross-cultural communication is successful or not. As YouTube is the most commonly used video-sharing platform in many countries and the most common way for Li Ziqi to gain international fans, this article analyzed her YouTube videos, subscribers, and fan interactions to determine cross-cultural communication. The analysis method proposed by Information Research in regards to YouTube comments was used to analyze the effectiveness of crosscultural communication from Li Ziqi's videos by classifying the comments on her videos to identify the viewer reactions and if they interacted with the culture shown in the videos. Our results found that most of the video comments are impression comments, which do not indicate much cross-cultural communication. These findings are significant in that they provide paths for more cross-cultural communication in the future and show how similar content can be used to promote cross-cultural communication.
\end{abstract}

Keywords: Li Ziqi; cross-cultural communication; analysis; YouTube; comments

Notes on the contributor: Devin Grace O'sullivan is a graduate student at the College of Foreign Languages, Taiyuan University of Technology, Taiyuan, China. Her main interests are Translation Studies, Intercultural Communication, and Literature. E-mail: devin.g.osullivan@ gmail.com.

\section{Introduction}

Li Ziqi is a popular Chinese blogger known for creating beautiful videos that feature an idyllic rustic lifestyle. This article will analyze her YouTube channel to see if she effectively communicates with people of other cultures, as many Chinese people believe that she would be an excellent example of Chinese culture to show to the world, also known as cross-cultural output. She exemplifies a peaceful, self-sufficient, and low-waste lifestyle that differs greatly from many modern ways of life. Using methods from the University of Boras, we can analyze if Li Ziqi's videos are successful cross-cultural communication, based on the comment section of three of her videos and the comment sections of some react videos. 


\section{Context}

Li Ziqi is extremely popular with young urban millennials in China. Part of the interest in Li Ziqi may come from the recent idea of fugu, which is a movement based around the growing appreciation in modern China for traditional culture (Yang 2020). Her videos are mainly based on food and traditional food preparation methods. She shows traditional Chinese clothing, such as hanfu, and skillfully showcases traditional Chinese cooking methods. For these reasons, she can be seen as a promoter of Chinese culture. In an interview with Goldthread in September 2019, Li stated, "I simply want people in the city to know where their food comes from." In addition to her food videos, she also has videos about hand-made clothes and homemade makeup. Her videos are all filmed and produced in her rural hometown in Sichuan and only feature herself and occasionally her grandmother. Her videos feature many beautiful Chinese landscapes and are beautifully soothing to the viewer. Previously, she lived in a city working as a singer, DJ, and waitress but returned home after her grandfather passed away (Duan 2020). Her Chinese social media accounts have an impressive number of fans, with 22 million on Weibo, and 37 million on DouYin. Her videos are praised for their beauty and ability to idealize the rural Chinese lifestyle.

YouTube is often used to examine a blogger's cross-cultural communication ability. YouTube has over 1.8 billion users every month and is the most commonly used video-sharing site (Gilbert 2019). Some countries have geographic bans on YouTube, and in those countries, they have their local video-sharing sites. However, when looking at cross-cultural communication, the local video sharing sites are not as important as they will not include any interaction with other cultures. YouTube is owned by Google and is used by a high percentage of the population in 91 countries. The application and website are both available in 80 languages, with plans to expand to more languages and cultures. Many popular videos include cross-cultural communication topics, such as people from different countries trying each other's snacks and discussing their preferences. YouTube is the most popular social media in many countries, and the countries with the highest number of users are the United States, Brazil, Japan, India, United Kingdom, Germany, France, Mexico, and Turkey (Migiro 2018). Due to its prevalence in many countries around the world, YouTube is an excellent resource for viewing cross-cultural communication.

The most subscribed-to channels are T-Series with 141 million subscribers, PewDiePie with 105 million subscribers, and Cocomelon Nursery Rhymes with 85 million subscribers. T-Series is India's largest music record label. PewDiePie is a Swedish content producer who began with videos about video games, but he has since diversified his content. Cocomelon Nursery Rhymes is a YouTube channel based in the USA and produces animated music videos for children. Even among just the top three subscribed to channels, it is evident that YouTube is a multi-cultural, global video-sharing platform in many countries around the world. The top 20 channels include Russian channels, Brazilian channels, Korean channels, Spanish channels, and more. As YouTube is used around the globe, it was chosen to examine Li Ziqi's cross-cultural communication and global impact.

Li Ziqi broke a Guinness World Record at the beginning of 2021( Tee 2021). She is now the holder of the "most subscribers for a Chinese language channel on YouTube" title. Li Ziqi averages 7 million viewers per Video on her YouTube channel with a small production team of three people, including herself. Her YouTube channel has 14.2 million subscribers. This number of viewers and subscribers indicates she is a moderately popular YouTuber. Her YouTube success can be attributed to her peaceful and relaxing videos. The quiet noises of nature and cooking in her videos are soothing, and some viewers comment that they love to watch her videos after a 
long day in the office. Her videos are heavily edited, and the resulting visuals are nothing short of artistic. Her channel art is beautiful, and every screengrab looks like an independent film more than a cooking and lifestyle channel. The thumbnail image for each video is like art and doesn' $t$ necessarily indicate the content. Strong visuals, however, might interest a potential viewer. Contrasting colors, good use of light to create depth are some of the editing methods that draw in a viewer and create such appealing art. Other ways that she might draw in a viewer are her video titles. Her titles often are longer and include potential keywords that someone might search for, often unrelated to thumbnail art but another possible way to gain more viewers. For example, one of her videos has the thumbnail image of her riding on a horse with a blue dress and a red cloak. The image is striking and may convince a viewer to watch. The video title is "Kumiss and Roasted Whole Lamb", which does not match the thumbnail image, but this could play an interesting role as a viewer could want to understand the connection between the two. A roasted whole lamb is a more commonly found searched-for phrase so that viewers could find her video in those ways. Many YouTube creators have either discovered through trial-and-error or analyzed to determine which time of thumbnail images and titles garner the most views. Many YouTube creators discovered that thumbnails with their images are effective, but titles need to have more information in them. From this perspective, the image where Li Ziqi rides a horse in a red cloak while the title is about roasted lamb is an effective way to attract viewers, particularly new ones. Older fans may simply watch a new video as soon as it comes out, but gathering new fans is also important to a YouTube creators' success. They need more fans and more views, so titles and thumbnail images are important. According to an article by Mint, a YouTube video creator can expect to make between $3 \$$ to $5 \$$ for every 1, 000 views that a video gets (Mint 2020). From this snapshot of her YouTube channels, it is clear that Li Ziqi is effective at gathering interest for her unique videos. Her videos rely on a high level of artistry and storytelling that takes the viewer on an enjoyable visual journey. Due to her videos' artistic and soothing nature, she has many fans who religiously watch her videos and even some fans who watch them every night to relax enough for sleep.

Internet communication is a relatively new form of communication, and we must include notes about the efficacy of this type of communication. Internet communication is most effective when it is reinforcing relationships built by in-person interactions (Kaveri 2008), but it can also be used to build new relationships. For educators, online communication is becoming more and more prevalent, so effective online teaching is critical to adapt to these changes. The seven criteria proposed by Suzanne Young to evaluate the effect of online teaching are: adapting to student needs, using meaningful examples, motivating students to do their best, facilitating the course effectively, delivering a valuable course, communicating effectively, and showing concern for student learning (Young 2009). Internet communication can be used for various purposes, but just like in-person communication, some things facilitate effective communication and things that can lead to miscommunications. When we examine communications that occur online, we must consider the factors that determine whether or not the communication is more likely to be successful or more likely to end with miscommunications.

Cross-cultural communication is defined as communication between people who have differences in nationality, ethnicity, and race. Some broader definitions also include communications between people of different ages, genders, work styles, etc. For this article, we will focus on the more narrow definition of nationality, as we are looking at some traditional aspects of rural Chinese life being shared worldwide. The main roadblocks to effective cross-cultural communication are ethnocentricity, language differences, nonverbal signals, and preconceptions. Ethnocentricity is the idea that one's own culture is normal and other cultures are strange or lesser. Language differences, mainly when someone is working in a non-native tongue, can limit the understanding of one 
party and limit the ability to share ideas. Non-verbal signals are things we do with our bodies or faces that mean different things depending on the culture. Preconceptions, also known as stereotypes, are problems that begin before communication has even started. Defining people before even knowing them does not allow for communication to grow as freely as it otherwise could. When we examine cross-cultural communications, we need to be prepared to identify the existence of any of these roadblocks.

Some information about modern Chinese culture is crucial to the understanding of internet stars such as $\mathrm{Li}$ Ziqi. For example, idol culture in China is a growing part of many young people's lives. Many people will not only promote their idol on social media, but they also spend their money to support their idol. As reported by China Daily, one fan named Lin spent half of her money on "cloud-raising her son," which is an average of 20, 000 a year. In 2019, Weibo reported USD 58 million in only the first quarter (Lei 2020). Idol fans will feel they need to protect their idols from those who mean them harm and buy products that their idol promotes. Idols are often required to have a squeaky-clean image, so fans believe they need to protect their innocent idols. This attitude can lead fans to be defensive of their idol and very willing to open their wallets to support them.

Live streaming and bullet chats are more interesting ways that Chinese idols sometimes choose to engage their fans. Idols will live-stream themselves doing their makeup, making food, doing crafts, or even just chatting to the camera. Additionally, comments by the viewers can cross the screen as bullet chats, in which viewers get to engage with each other and the idol. Some apps even allow for monetary gifts to be given to the idol, which some idols will respond to live on their video. These are more channels for communication and more engaging content; however, as these methods of communication are mainly on Chinese apps that have minimal popularity in other countries, we will not be analyzing them for cross-cultural communication. Modern Chinese culture regarding idol and fan relationships is often unfamiliar to those in Western cultures, so this brief introduction aims to serve as a bridge to understanding this topic.

\section{Research Methods}

A study done by the University of Boras in Sweden found that YouTube comment sections can supply useful information about the cultural-communication value of a channel. They found that one important factor when analyzing a YouTube channel's cross-cultural communication potential is the language and nature of comments in the comment section. The comment part that shares cultural information involves cultural issues, reflection on their own culture and finding common ground, which is the pillar to determine the successful cultural exchange in YouTube Videos ( Kim 2019). These findings confirm what most people can guess about cross-cultural communication- the most successful cross-cultural communication is a two-way street where every culture involved in the communication is respected and treated as equal and does not promote the attitude of ethnocentrism. A comment section with more discussion, personal experience sharing, and teaching about cultures will share more information about a culture.

A channel called The Korean Englishman is an example of successful cross-cultural communication. Londoners who live in Korea and speak Korean interview Koreans and introduce other people to aspects of the culture. This channel has garnered 500 million views and has videos such as English people trying Korean food and English priest going to Korea. Their videos are made to educate English people about Korean culture, and the comment section is filled with engaging debates about the differences between the two cultures. The videos are informative, and the comment section is even more informative, as Korean people, English people, and people 
from other cultures discuss the cultural differences. The comments on these videos can be classified as general conversation, information, impression, reflection, and question and answer comments. Information comments and general conversation comments can be some of the strongest indicators of successful exchanges of cultural information, as well as question and answer comments. The comment sections of this channel have many of these types of comments. This video can also be considered successful cross-cultural communication as the viewers and commenters do not often demonstrate an ethnocentric attitude. They do not promote their culture as the best: instead, they appear to be genuinely curious about other cultures. Ethnocentrism is a barrier to successful cross-cultural communication. The study and looking for non-ethnocentric comments are the ways that Li Ziqi's YouTube channel can be analyzed for successful cross-cultural communication.

For this study, we will sample comment sections of Li Ziqi YouTube videos. The comments will be sorted based on the University of Boras's categories. In this way, we hope to bring insights into any potential cross-culture communication done by Li Ziqi's videos. As it would not be time-effective to categorize thousands of comments, we chose to focus on the top 25 comments on several videos. YouTube's algorithms for comment viewing allow comments that receive comments and like to be sorted to the top, so comments that generate discussion will be sorted towards the top. In this way, we can see the comments that garner the most interest and most conversation on her videos, which can allow us to see the communications taking place in the comment section of the YouTube videos. While the less popular comments may hold insights into the cross-cultural communication taking place on her channel, we believe that the top comments will be the most relevant to their research, as these comments will be those with the most interactions.

\section{Analysis}

An important note before the analysis begins is that Li Ziqi does not state her own goals are to share Chinese culture with the world, nor does she set out intending to effectively communicate across cultures. In her interviews, she states that she wanted to show city people where their food comes from. Based on her popularity with urban Chinese millennials, she has been very successful in this goal. Analyzing her YouTube for cross-cultural communication signaling is simply a method of seeing how her viewers perceive her videos and is not a judgment on her videos or her successes in achieving her goals.

Out of the sampled 25 comments on her "Kumiss and Roasted Whole Lamb," only 1 is classified as an informative comment. This shows that the comments on the video are rarely classified into the information category, in which someone familiar with the culture is explaining a practice or aspect of the video to someone unfamiliar with it. The Korean channel used in the study had information comments which composed over $25 \%$ of the total comments. General conversation comments are also rarely found on this video. These comments are conversations between viewers that discuss the video and even sometimes conversation with the creator of the video. The rate in the study marked general conversation comments at $15.4 \%$. These conversations show that viewers wish to engage with others and learn about the culture together. Out of the 25 comments on her "Kumiss and Roasted Whole Lamb" video, 2 are general conversation comments that lead to in-depth discussions. The overwhelming majority of comments on this video were impression comments, with 20 comments giving Li Ziqi compliments or expressing interest in the content. For the Korean channel, impression comments are the least frequent. The remaining 2 comments were viewers comparing their personal experiences to the content of the video, also known as reflection comments. 
The 25 top comments on her "Make a peach blossom crown with silk flowers" had a relatively similar comment spread. There was 1 information comment, 1 general conversation comment, 19 impression comments, and 4 reflection comments. The information comment that was in the sample was a Chinese speaker who wrote a Chinese and English transcript in the comments, as well as some commentary. The transcript garnered hundreds of comments and is a strong example of cross-cultural communication. The general conversation comment was telling the other viewers a little about Li Ziqi's past. Reflection comments were mainly focused on comparing the lifestyle shown in the video to the commenter's own life, and the impression comments were entirely praising $\mathrm{Li}$ Ziqi.

The third video that was chosen for analysis was titled "The life of cucumbers", and it had 30 million views. The top 20 comments had the following breakdown: No information comments, 2 comments that are considered general conversation, 21 comments that can be categorized as impression, and 3 comments that are reflection comments. Similar to the previous videos that we analyzed, most sampled comments discussed the beauty of the videos and praised Li Ziqi for her work. One of the general conversation comments was interesting in that the commenter expressed interest in learning skills from Li Ziqi and noted that they would have to learn Chinese for it.

In addition to our analysis, we also viewed other videos relating to Li Ziqi, and read comments on those videos. While viewing some such material, we noted another barrier to cross-cultural communication. A popular type of YouTube video, React Video, is the video in which the viewer watches someone else watch the video and comment their impressions. React videos can be excellent tools for cross-cultural communication, as they can show someone from one culture seeing another culture and commenting on it, and the viewer might be from a third, unrelated culture. One such react video filmed by Enu Create, a channel that aims to help YouTube creators reach a larger audience, had a negative comment section. Her video mainly praises Li Ziqi and talks about the nature of her videos and some reasons why she thinks her channel has gotten 7 million fans. The comment section is filled with a mixture of Chinese and English comments criticizing Enu Create, saying that she is overanalyzing Li Ziqi's production, asking her to stop, and telling her that Li Ziqi makes videos for art, not for viewers. The comments often are defensive of Li Ziqi and have ethnocentrism attitudes. Her fans idolize her and insist that the culture and skill shown in her videos are the best in the world. A comment section filled with discussions, questions, and information would have shown that the fans of Li Ziqi's YouTube channel are invested in sharing their own culture and learning about other cultures. Whereas Li Ziqi's YouTube fans seem to view her as more of an idol than as a content creator who gives a unique introduction to Chinese culture. The video, as that of 2021, was removed by the creator.

Other react videos, such as one done by Blondie in China titled "My parents watch LIZIQI for the first time", have a more positive comment section. The comment section was mainly impression comments, with viewers expressing admiration for Li Ziqi and a fondness for the father in the video. There are more information comments on this video, with viewers explaining some of the foods seen in the videos. The information comments seen here are examples of cross-cultural communication that shares aspects of Chinese culture with the viewers of the channel Blondie in China. One reason why the comment section may have more information comments is that the three people commenting on the video are English people with limited knowledge of the video. If a viewer has more knowledge than the creators do, they are likely to share that knowledge in the comment section. While the video creator may not read every comment, other people in the comment section can also share the benefit of learning more about the culture. In this way, we can see how to react videos can often be informa- 
tive and strong examples of cross-cultural communication, even if the creator themselves does not have a strong grasp of the culture they are reacting to.

\section{Conclusion}

Based on these criteria for successful cross-cultural communication, Li Ziqi's YouTube channel is not a strong example of cross-cultural communication. Her viewers are impressed by her skills and the beauty of the videos, but there are few cultural discussion, reflection, or question-and-answer style comments. From this analysis, it is clear that the main impact of her videos is not cross-cultural communication, and her viewers do not watch her YouTube videos to learn more about Chinese culture. Her videos, however, still show aspects of Chinese culture even if they do not spark discussion or education on the topic.

Li Ziqi is a content creator whose content positively features Chinese culture, and her videos can be considered cultural output for this reason. Her videos show her way of life, which is an idealized form of rural Chinese life, from clothes to makeup to food. The soothing nature of her videos can take away some of the anxiety and uncertainty that can be a barrier to understanding unfamiliar cultures. She achieves her goal of showing urbandwellers where their food comes from, and also successfully creates beautiful and relaxing videos that shine a spotlight on some traditional aspects of Chinese culture. The content in her videos mirrors the modern person's hunger for a more simplistic, less-wasteful lifestyle, so she has gained popularity. Li ZiQi is a unique creator who shows interesting parts of Chinese culture, and her videos can introduce aspects to Chinese culture. Her videos do not directly inspire cross-cultural communication, and they are not educated in the traditional sense. Her YouTube channel comment sections and how her fans idolize her show that the main impact of her channel is not cross-cultural communication; however, her videos may have the added benefit of sharing some parts of Chinese culture with her viewers.

However, her videos can inspire cross-cultural communication when paired with additional commentaries, such as a react video. React videos, where people from both cultures come together to discuss material, can lead to a better understanding of cultural aspects. In this sense, videos created by Li Ziqi can be seen as the source material or tool that other creators can use to share parts of the culture. Her videos are beautiful and introduce many ideas, but the lack of language or explanations of what is happening means that her videos are left lacking as a form of cross-cultural communication.

Cross-cultural communication often relies on a form of teaching: both parties must learn more about the culture they are hoping to communicate with to avoid misinterpretation. In that sense, cross-cultural communication that relies on the internet should consider the tenets of effective online teaching. While YouTube videos would be hard-pressed to adapt to students' needs or motivate them, they can ensure the material they aim to share is communicated clearly. For material that would promote cross-cultural communication, some relevant information would be the cultural phenomenon they are introducing, the history and reason behind it, and the impact it has on modern members of the culture. Li Ziqi successfully shares beautiful snapshots of her own life, and some traditional aspects of rural Chinese life, but to an outsider of the culture, the videos may simply be beautiful art as there is no greater teaching or meaning showcased in the video. To create a better opportunity for cross-cultural communication, a video creator could use Li Ziqi's videos as a source material while explaining what she is doing, the cultural significance, and how that relates to modern Chinese people.

In conclusion, Li Ziqi makes beautiful videos that excel at showing urban people an idyllic version of rural 
Chinese life. Her videos are popular for their artistic aesthetic and interesting topics; however, when analyzed from the point of cross-cultural communication, her videos are not as successful as other creators. The nature of her videos is to show viewers her way of life, not to explain or introduce things to a foreign audience. There is also little two-way communication between her and her fans, which makes cross-cultural communication more difficult. Lastly, the comment sections of her videos show that her fans are most interested in the beauty and peace that her videos are known for and that most international fans will not begin discussing Chinese culture or be able to interact with her Chinese fans in a meaningful way. Li ZiQi can be upheld as an example of the ideal rural Chinese life. Li Ziqi also attracts Chinese urban millennials, and her videos are excellent at bridging the gap between rural and urban China. Her videos accomplish her personal goals of showing the rural way of life and have a secondary benefit of showing some aspects of traditional Chinese life to her viewers. Under the broader definition of cross-cultural communication, in which urban to rural communications can be considered a form of cross-cultural communication, she is successful at sharing parts of her rural life with her urban Chinese counterparts. From a narrower definition of cross-cultural communication, in which we examine the cultures held by different countries, races, or ethnicities, Li Ziqi's videos do not exemplify a strong example of cross-cultural communication.

\section{References}

Tee, J. (2021). What's the story behind Li Ziqi and her record-breaking YouTube videos? South China Morning Post. Available online: https://www.scmp.com/magazines/style/celebrity/article (accessed on February 17, 2021)

Mint. (2021). How much do YouTubers make \& how to become a YouTuber. MintLife Blog. Available online: https://mint.intuit.com (accessed on April 23, 2021)

Lei, Z. (2020). Fans will go to any lengths to promote their idol. Chinadaily. Available online: http://www.chinadaily.com.cn.

Goldthread. (2019) . Exclusive interview with Li Ziqi, China's most mysterious Internet celebrity. YouTube.

Kim, A., Caidi, N. \& Chah, N. (2019) . "Our Korea”: Transcultural affinity as negotiated through ... Information research. Available online: https: //www.researchgate.net. ( accessed on March, 2019)

Duan, X. E. (2019) . "Rural net red" Li Ziqi rushed out of the world and was blessed by Chinese official media. Have you seen her video? The Initium. Available online: https://theinitium.com ( accessed on December 17, 2019)

Migiro, G. (2018). Which countries watch the most on youTube? WorldAtlas. Available online: https://www. worldatlas.com. (accessed on November 30, 2018)

Gilbert, B. (2018). YouTube now has over 1.8 billion users every month, within spitting distance of FACEBOOK's 2 billion. Business Insider. Available online: https://www.businessinsider.com (accessed on May 4, 2018)

Subrahmanyam, K. \& Greenfield, P. (2008). Online communication and adolescent relationships. The Future of Children, 18( 1), 119 -146 .

Yang, C. M. (2019, April 10) . China's cultural Revivalists: More than just QUIRKY THROWBACKS. Sixth Tone. Available online: http://www.sixthtone.com (accessed on April 10, 2019)

Young, S. (2006). Student views of effective online teaching in higher education. American Journal of Distance Education, 20(2), 65 -77 . 